
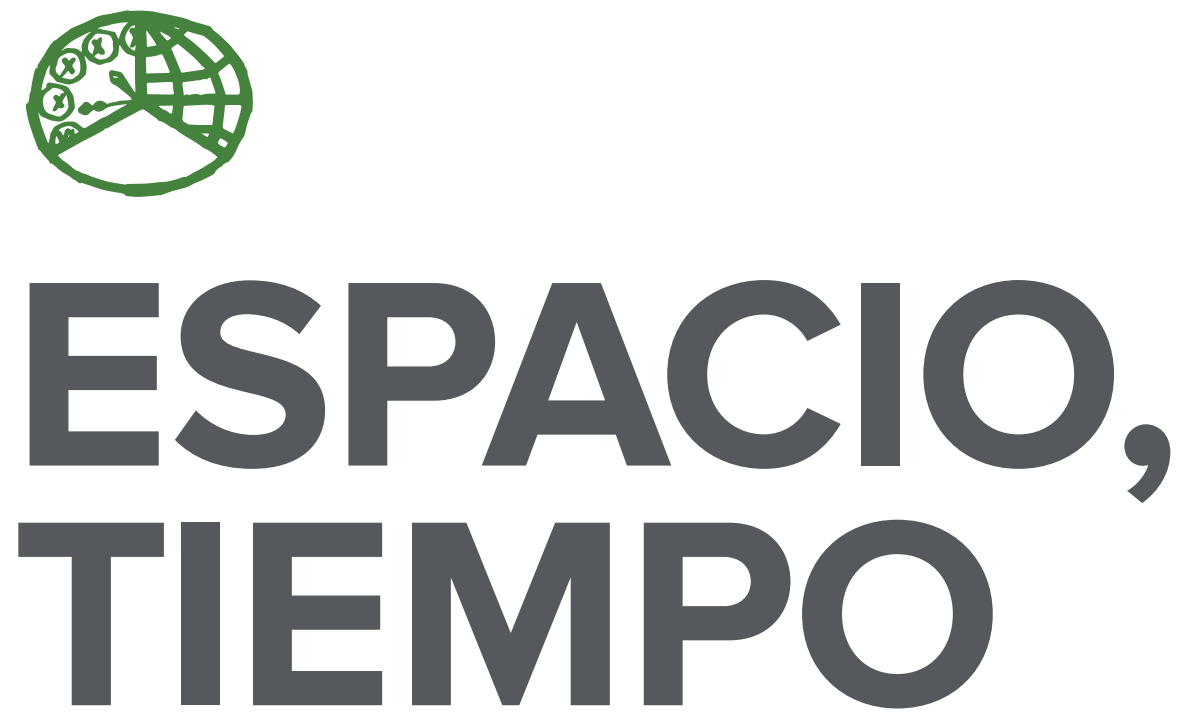

AÑOS 2015-2016

ISSN 1130-2968

E-ISSN 2340-146X
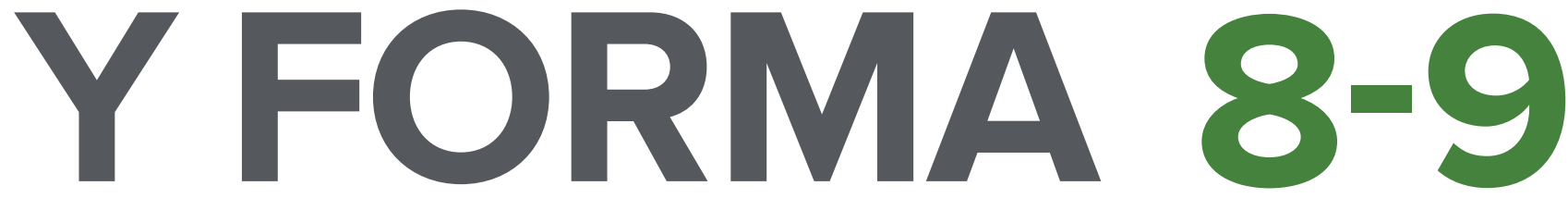

SERIE VI GEOGRAFÍA

REVISTA DE LA FACULTAD DE GEOGRAFÍA E HISTORIA 

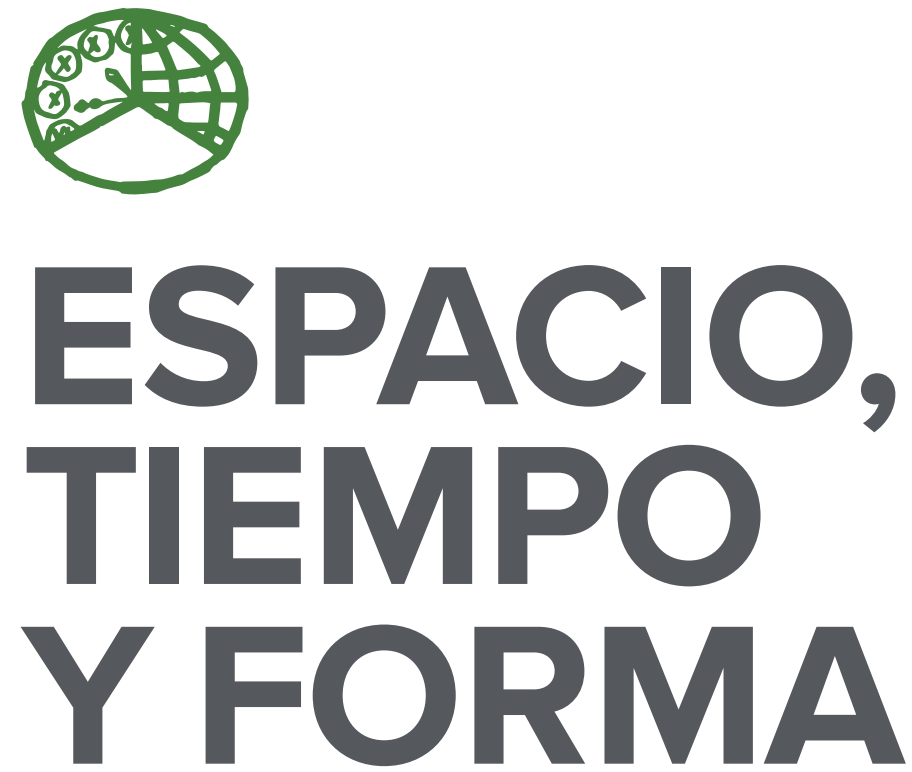

AÑOS 2015-2016

ISSN 1130-2968

E-ISSN 2340-146X

SERIE VI GEOGRAFÍA

REVISTA DE LA FACULTAD DE GEOGRAFÍA E HISTORIA

DOI: http://dx.doi.org/10.5944/etfvi.8-9.2016

\section{UกED}

UNIVERSIDAD NACIONAL DE EDUCACIÓN A DISTANCIA 
La revista Espacio, Tiempo y Forma (siglas recomendadas: ETF), de la Facultad de Geografía e Historia de la UNED, que inició su publicación el año 1988, está organizada de la siguiente forma:

$$
\begin{aligned}
& \text { SERIE I - Prehistoria y Arqueología } \\
& \text { SERIE II - Historia Antigua } \\
& \text { SERIE III - Historia Medieval } \\
& \text { SERIE IV - Historia Moderna } \\
& \text { SERIE V - Historia Contemporánea } \\
& \text { SERIE VI - Geografía } \\
& \text { SERIE VII - Historia del Arte }
\end{aligned}
$$

Excepcionalmente, algunos volúmenes del año 1988 atienden a la siguiente numeración:

$$
\begin{aligned}
& \mathrm{N}^{\circ} 1 \text { - Historia Contemporánea } \\
& \mathrm{N}^{\circ} 2 \text { - Historia del Arte } \\
& \text { N. }{ }^{\circ} 3 \text { - Geografía } \\
& \mathrm{N} .^{\circ} 4 \text { - Historia Moderna }
\end{aligned}
$$

ETF no se solidariza necesariamente con las opiniones expresadas por los autores.

Espacio, Tiempo y Forma, Serie vi está registrada e indexada, entre otros, por los siguientes Repertorios Bibliográficos y Bases de Datos: DICE, ISOC (CINDOC), RESH, IN-RECH, Dialnet, e-sPacio, UNED, CIRC, MIAR, FRANCIS, PIO, ULRICH'S, SUDOC, 2DB, ERIH (ESF).

\author{
UNIVERSIDAD NACIONAL DE EDUCACIÓN A DISTANCIA \\ Madrid, 2015-2016 \\ SERIE VI · GEOGRAFÍA N. ${ }^{\circ} 8-9,2015-2016$ \\ ISSN 1130-2968 · E-ISSN 2340-146x \\ DEPÓSITO LEGAL \\ M-21.037-1988 \\ URL \\ ETF VI · GEOGRAFÍA $\cdot$ http://revistas.uned.es/index.php/ETFVI \\ COMPOSICIÓN \\ Carmen Chincoa Gallardo · http://www.laurisilva.net/cch
}

Impreso en España · Printed in Spain

(c) (7) (8) Esta obra está bajo una licencia Creative Commons

Reconocimiento-NoComercial 4.0 Internacional. 


\title{
TRES TESIS DOCTORALES DIRIGIDAS POR DON MANUEL DE TERÁN: EL PAISAJE RESIDENCIAL EN MADRID (DOLORES BRANDIS), LA ENSEÑANZA EN MADRID (ANA OLIVERA) Y EL BARRIO DE SALAMANCA (RAFAEL MAS) ${ }^{1}$
}

\section{THREE THESIS DIRECTED BY DON MANUEL DE TERÁN: EL PAISAJE RESIDENCIAL EN MADRID (DOLORES BRANDIS), LA ENSEÑANZA EN MADRID (ANA OLIVERA) Y EL BARRIO DE SALAMANCA (RAFAEL MAS)}

\author{
Aurelio Nieto Codina² \& Dolores Brandis García \& Carlos J. Pardo Abad 4 \\ Recepción: 11/09/2015 · Aceptación: 10/12/2015 \\ DOI: http://dx.doi.org/10.5944/etfvi.8-9.2016.16370
}

\begin{abstract}
Resumen
La investigación geográfica en España tiene en Manuel de Terán unas de sus personalidades clave, sus aportaciones científicas y su experiencia docente han marcado la evolución de nuestra disciplina; además, su presencia en el mundo académico y cultural hacen de él una figura imprescindible para entender la evolución de la ciencia en nuestro país. Ejemplificamos su labor como promotor de la investigación geográfica glosando tres tesis, que se encuadran dentro de los estudios referidos a la geografía urbana de Madrid, una de las líneas de investigación prioritaria del maestro. En primer lugar, el análisis del barrio de Salamanca, fragmento clave del ensanche histórico madrileño en su sector NE, obra de Rafael Mas. Después, la evolución histórica del paisaje residencial de Madrid y sus ejemplos tipo hasta la década de los setenta, realizada por Dolores Brandis. En tercer lugar, el estudio de la enseñanza en Madrid, una función urbana básica y un derecho de los ciudadanos estudiada por Ana Olivera. Estas obras son testimonio, entre otras, de la existencia de una escuela geográfica surgida de Manuel de Terán.
\end{abstract}

1. Agradecimiento: Este trabajo no podría haberse desarrollado sin la colaboración desinteresada de Ana Olivera, Dolores Brandis y Carlos J. Pardo Abad.

2. Departamento de Geografía, Universidad Nacional de Educación a Distancia.<ancodina@geo.uned.es>.

3. Departamento de Geografía, Universidad Complutense de Madrid. <dbrandis@ghis.ucm.es>.

4. Departamento de Geografía, Universidad Nacional de Educación a Distancia. <cjpardo@geo.uned.es>. 
Palabras Clave

Investigación geográfica; geografía urbana; escuela científica; Ensanche; promoción inmobiliaria; viviendas; paisaje urbano; enseñanza; función urbana.

\begin{abstract}
In Spain, Manuel Teran was some of its key personalities in geographical researchers, their scientific contributions and his teaching experience have marked the evolution of this discipline; in addition, its presence in the academic and cultural world make it an indispensable tool for understanding the evolution of science in our country. We exemplify its work in promoting geographical research glossing three theses, which fall within the studies related to the urban geography of Madrid, one of the priority research lines of the teacher. First,the analysis of the Salamanca district of Madrid historical key fragment extension in its NE Ensanche, written by Rafael Mas. Then, the historical evolution of residential landscape of Madrid and typical examples until the early seventies by Dolores Brandis. Third, the study of education in Madrid, a basic urban function and a right of citizens studied by Ana Olivera. These works testify, among others, of the existence of a geographical school emerged from Manuel de Terán.
\end{abstract}

\title{
Keywords
}

Geographical research; urban geography; scientific school; Eixample; property development; housing; cityscape; education; urban function. 
EN ESTA SEGUNDA ENTREGA de nuestro repaso a la evolución de la Geografía en España, rendimos tributo de una manera peculiar al que probablemente sea uno de los intelectuales españoles más importantes de su tiempo: Don Manuel de Terán. Una personalidad fundamental tanto en el campo de la investigación como de la docencia geográfica, que al mismo tiempo supo trascender los límites de la Geografía incorporando a sus líneas de trabajo temáticas novedosas que hasta que él no las abordó parecían exclusivas de otras disciplinas (sociología, antropología, etc.). Las novedades temáticas y metodológicas en la obra de Manuel de Terán se solapan junto a aspectos y tendencias que la geografía ya estaba desarrollando desde mediados del siglo XX; de este modo, supo aunar tradición y novedad en una inteligente simbiosis.

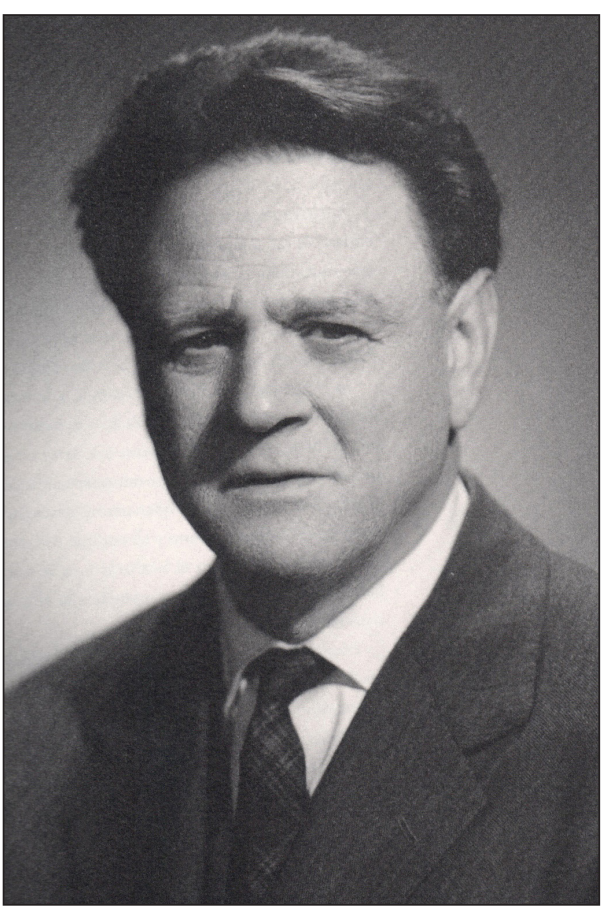

La significación global de su trabajo abarca, desde aspectos epistemológicos, como su reflexión sobre la causalidad en geografía, hasta sus aportaciones a la ciencia del paisaje, sus relaciones con el entendimiento general de las ciencias naturales o, dentro de parámetros más tradicionales, su atención a la geografía general (en esa magna obra que es Imago Mundi), o su peculiar aportación al estudio de las escalas de gran detalle (nos referimos al trabajo seminal acerca de las calles madrileñas de Alcalá y Toledo). Una mente de tan amplias miras y una obra de tanto alcance encuentra su desarrollo no sólo en función de los trabajos realizados individualmente, sino que se amplía en función de un numeroso grupo de discípulos que genera una auténtica escuela, entendida esta en el sentido más amplio de la palabra. La escuela de Terán la forman un nutrido grupo de investigadores que han profundizado sus líneas de investigación y que han ampliado las enseñanzas del maestro en nuevas generaciones de geógrafos. Este es el aspecto del que queremos dejar constancia a través de los siguientes textos, en los que se valoran tres tesis doctorales dirigidas por el maestro y que por si mismas son hitos en la historia de la geografía relacionada con temas matritenses ${ }^{5}$. No queremos con esta selección establecer aquí una supuesta jerarquía de valor y situar los ejemplos en una inexistente cúspide; todos los trabajos realizados bajo la supervisión de Manuel de Terán tienen una particular importancia

5. Aclarar que realmente lo que estamos glosando son los libros publicados a partir de estas tres tesis doctorales que incluso varían en los títulos elegidos finalmente en los libros publicados. Rafael Mas Hernández (1977), Estudio geográfico del sector NE del Ensanche de Madrid, luego publicado como El Barrio de Salamanca. Dolores Brandis García (1979), La evolución histórica del paisaje residencial en Madrid, luego publicada como El paisaje residencial en Madrid. Ana Olivera Poll (1977), que mantiene el mismo título en la tesis y en la publicación: La enseñanza en Madrid. 
y aportaron sus propios valores al conocimiento de diferentes áreas de la geografía. La selección de estos tres ejemplos se establece en función de sus singulares aportaciones científicas, tanto por la peculiar aportación de los temas propuestos, como porque dan una visión clarividente de aspectos fundamentales del espacio urbano madrileño. Al mismo tiempo, se ha buscado un diálogo generacional entre discípulos directos del maestro homenajeado y quienes nos podríamos considerar la tercera generación de discípulos que seguimos sus directrices, aunque sea de manera indirecta por intercesión de quienes sí que lo conocieron personalmente.

Una de las aportaciones científicas más importantes de Manuel de Terán fue la ampliación de las escalas temáticas, la búsqueda de temas novedosos que no se restringieran a lo que se estudiaba hasta ese momento en la universidad española. En el fondo, lo que buscaba con esta ampliación del ámbito temático era ahondar en todos los aspectos que explican la realidad geográfica, que no es otra que la síntesis de lo físico y lo humano. En este sentido, los rasgos geográficos solo se explican desde la trabazón de las aportaciones naturales, demográficas, sociales y culturales. Utilizando palabras del propio Terán, «la geografía no está inscrita únicamente en el suelo, la hacen los hombres contando con éste y a veces en contra de éste, pero lo que los hombres hacen sobre el suelo no es puro artificio, es geografía con el mismo derecho que la que se realiza al dictado de las condiciones físico-naturales» ${ }^{6}$.

Julio Múñoz Jiménez ha analizado el trabajo de Manuel de Terán como promotor de la investigación geográfica en España, señalando la dirección durante veinticinco años de nada menos que 3I tesis doctorales y 157 memorias de licenciatu$\mathrm{ra}^{7}$. Unas cifras extraordinarias tanto para los estándares de la época como para la actualidad $^{8}$. La mayor parte de las tesis leídas corresponden al periodo I97I-I982, un momento en el que predominan los estudios dedicados a la geografía urbana, especialidad en la que se inscriben los tres trabajos que detallamos a continuación. Los trabajos dirigidos sobre geografía urbana de Madrid y su área metropolitana tienen una presencia destacada en el conjunto citado, las escalas utilizadas varían desde las visiones de conjunto hasta la atención puntual a distritos y barrios, tanto del centro y el ensanche históricos como de las nuevas periferias que crecen sobre todo durante el desarrollismo (Cuatro Caminos de Martínez de Pisón, Barrio de Salamanca, de Rafael Mas, el casco antiguo de Ruiz Palomeque o el distrito de Carabanchel de Antonio Moreno); en otras ocasiones, se estudian aspectos más puntuales en relación al paisajes o a las funciones urbanas, adecuando la escala según la temática elegida (los transportes del Sureste de Antonio Abellán, La vivienda según Dolores Brandis, la enseñanza de Ana Olivera, la industria en Villaverde de Isabel del Río o la geodemografía metropolitana de Julio Vinuesa).

6. TERÁN (1976), p. 9.

7. CATÁlogo (2007), p. 213.

8. Hasta el año 1965 la práctica totalidad de las tesis de geografía de la universidad correspondían a la supervisión de Manuel de Terán y José Manuel Casas Torres, manteniéndose su protagonismo al menos hasta el comienzo de la democracia. 
Una semblanza personal de cómo era el trabajo de supervisión de tesis por parte de Manuel de Terán lo ha realizado Ana Olivera ${ }^{9}$, pero debo a su generosidad un fragmento de un texto inédito dedicado al maestro que no me resisto a trascribir para cerrar este modesto prólogo. Sirvan estas palabras de homenaje a un geógrafo ejemplar, al tiempo que nos ilustran acerca de los valores como investigadores que supo inculcar a sus discípulos.

«Cuando la fuente (del saber científico de Manuel de Terán) se desbordaba más generosamente y manaba fluida hacia nuestros ávidos cerebros juveniles era durante las sesiones de supervisión de tesis, aparentes diálogos informales, relajados, tomándose su tiempo, que eran modélicos ejemplos de discusión socrática. En esos minutos que dedicaba a cada uno de nosotros en exclusiva, sin prisas, mientras mordía y acariciaba una pipa que rara vez echaba humo, nos transmitió contenidos, nos reveló procesos y nos enseñó a investigar en Geografía. La labor de dirección de tesis la realizaba algunas veces en el Departamento de Geografía de la Universidad Complutense, muchas otras en su propio domicilio (la gran trastienda del sabio, donde los libros se adueñaban impunemente de estantes, mesas, sillas, sillones, pasillos, etc... haciéndolos inutilizables) y las más en el antiguo Instituto Elcano, en aquel momento situado en la planta superior del edificio central del C.S.I.C.

Como supervisor de tesis nos enseñaba a preguntarnos a dónde llegar y cómo conseguirlo, aunque teníamos que encontrar la solución solos ... Así lograba el objetivo final de toda tesis, que es formar investigadores autónomos, que puedan dirigir sus propias investigaciones y las de otros, y no la mera comprobación de hipótesis. Pero lo más importante es que transmitía pasión por esa labor, ilusión, rigurosidad, y hacía que entendiéramos que el oficio de investigar tiene mucho de creatividad, precisa sosiego, sedimentación, tiempo, poso, ritmo, a veces soledad, otras cooperación o dialéctica y, en algunos momentos, febril desesperación.»

\section{RAFAEL MAS HERNÁNDEZ: EL BARRIO DE SALAMANCA}

Dolores Brandis García. Departamento de Geografía, Universidad Complutense de Madrid.

Corría el año I972 cuando Rafael Mas propuso a Manuel de Terán hacer su tesis doctoral sobre el Barrio de Salamanca, uno de los ámbitos más claramente burgueses del Ensanche madrileño. El profesor le miró perplejo. Los estudios que había dirigido sobre Madrid trataban barriadas de residencia obrera que reclamaban ser estudiadas y publicadas para así dar a conocer su situación desfavorecida y oculta. Esa era la filosofía del maestro. No obstante invitó al alumno a responder a la siguiente pregunta: ¿qué me puede decir del barrio de Salamanca que merezca una tesis? Y el discípulo convenció al maestro. Cinco años después, en I977, Rafael Mas defendía su tesis doctoral en la Facultad de Geografía e Historia de la Universidad Complutense de Madrid.

9. CATÁLOGo (2007), pp. 335-338. 


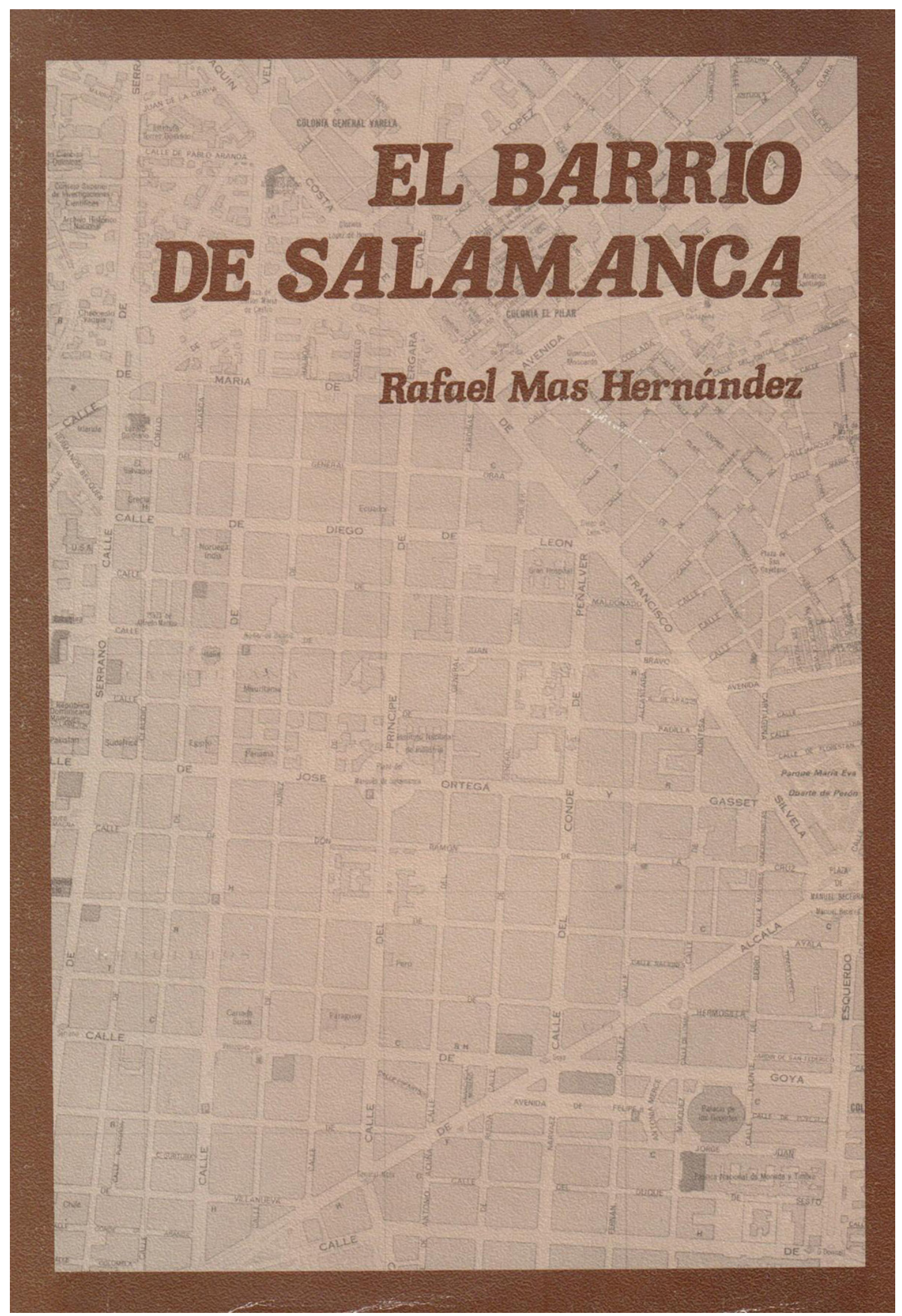


Pocos conocen que el título de la tesis fue otro. Un título más formal y al uso en la disciplina del momento: «Estudio geográfico del sector NE del Ensanche de Madrid». Cuando en I982 el Instituto de Estudios de Administración Local se hace cargo de la publicación, brota el empeño inicial, con el que todos por aquel entonces identificábamos la investigación: «El Barrio de Salamanca». Para el contenido del libro el autor elige aquellos capítulos que responden al subtítulo que le acompaña «Planeamiento y propiedad inmobiliaria en el Ensanche de Madrid». Pero el resto de la tesis también se publica. Lo hace en 1978 en forma de artículos: «La tipología de viviendas» en Estudios Geográficos y el «Plano parcelario» $\mathrm{y}$ «La gestión inmobiliaria del marqués de Salamanca» en Ciudad y Territorio.

En la introducción del libro Rafael Mas da luz sobre las claves interpretativas del barrio: «el planeamiento urbano y las estrategias y modalidades de la propiedad inmueble se erigían en los verdaderos motores del espacio urbano. Todo ello, por supuesto, a través de un determinado marco construido» (...) «el análisis demográfico y socioeconómico parecía cada vez más tener relevancia sólo como efecto derivado o como consecuencia final». Se entiende, pues, que el análisis del planeamiento y la propiedad inmobiliaria cobren protagonismo en la investigación, tal y como reza el subtítulo del libro. Es aquí donde el autor hace los mayores avances en el estudio de los espacios urbanos españoles y que es necesario resaltar. A ellos nos referimos a continuación.

La tesis incorpora una novedad temática nada usual en los estudios de geografía urbana al uso. Desentrañar el papel que desempeñaban al unísono el planeamiento, la propiedad urbana y la promoción inmobiliaria en los procesos de crecimiento de la ciudad permitía entender la configuración del espacio urbano y su diversidad social. Se ponen de manifiesto, y se alerta, de asuntos de gran trascendencia como la intervención municipal en el incumplimiento del inicial planeamiento y de lo legislado, a modo de concesiones que se hace a los agentes privados intervinientes, o el poder de la propiedad del territorio en el mercado de suelo urbano, o la imposición de determinadas prácticas inmobiliarias en la configuración del espacio construido. Asuntos, algunos, como la primacía de los intereses de los promotores sobre el alcance de las normas reguladores del planeamiento urbano, resaltados por aquel entonces por Fernando Terán en su libro sobre el planeamiento urbano en España publicado en 1978.

Rafael Mas procede al examen detallado de las prácticas de los agentes urbanos que con criterios de lucro capitalista actúan en el Ensanche madrileño. Y este empeño constituye su mayor aportación metodológica. En el análisis realizado se reconoce un método riguroso que se demuestra válido y eficaz hasta hoy, cuando más que nunca prácticas similares son habituales en los nuevos territorios urbanizados de las ciudades españolas. Se sirve de fuentes de información directa, poco empleadas en los estudios urbanos en ese momento, indispensables por el alto valor explicativo de la información y básicas para el conocimiento de las estructuras de la propiedad. El Catastro de la Riqueza Urbana, el Registro de la Propiedad o el Registro Histórico de Protocolos se someten a un exhaustivo y necesario análisis. También recupera mapas históricos, planos y parcelarios urbanos y fiscales arrinconados en archivos y oficinas, necesarios para identificar en el territorio la realidad 
de los hechos. Rescata del Archivo de Villa documentos oficiales de gran interés que desvelan el proceder administrativo. El procesado de todas estas fuentes le permiten ir descubriendo la conformación del territorio y desvelar las estrategias empleadas por los agentes que intervienen.

La relevancia del proyecto de investigación y del método empleado dio sus frutos que sintetizamos en cuatro apartados. En primer lugar, tres tesis bajo su dirección vieron la luz en los años noventa, orientadas a rellenar huecos imprescindibles para comprender en detalle la conformación urbana de la ciudad de Madrid. La de Elia Canosa (I990) sobre La promoción inmobiliaria en la periferia noreste de Madrid confía en el poder explicativo del análisis continuado de las promociones urbanas, entendidas como las operaciones masivas de venta de suelo urbano o de construcción y venta de viviendas, que contribuyen al esclarecimiento de las claves organizativas de la periferia. El empleo de las escrituras notariales de compraventas, los catastros de la riqueza rústica y urbana y los fondos del registro de la propiedad como principales fuentes de análisis contribuyen a ello. La tesis de Luis Galiana (I992) sobre Suelo público y desarrollo urbano: el caso de Madrid aparece centrada en la política municipal de suelo seguida en los últimos cincuenta años. Los análisis concienzudos del planeamiento, de las políticas de suelo, de su financiación, del patrimonio municipal o de las actuaciones públicas más importantes desarrolladas, a través de fuentes directas y hemerográficas, permiten dibujar un panorama diáfano del suelo de intervención pública en la ciudad y se constituye en un punto de referencia básico en lo relativo a políticas de suelo. Finalmente, Isabel Rodríguez Chumillas (1998) en su tesis La promoción privada de viviendas en Madrid. De los caseros a las inmobiliarias utiliza fuentes históricas directas para conocer los principales propietarios de inmuebles del último tercio del siglo XIX y su correspondencia en la morfología de la ciudad. El mismo interés le mueve al abordar el crecimiento inmobiliario de los últimos cincuenta años, explotando las fuentes directas pertinentes para su estudio, depositadas en dependencias municipales, archivos y registros.

En segundo lugar, la continuidad del proyecto y método iniciado se pone también de manifiesto en los estudios que Rafael Mas acometió durante treinta años, ampliando el conocimiento de las ciudades. Fueron años de una fecunda labor investigadora dedicadas a profundizar en el método y ponerlo en práctica en otros espacios urbanos, más allá del Ensanche madrileño y que le llevaron a traspasar el Atlántico. Una selección de esta producción publicada señalamos a continuación. Estudios centrados en profundizar en el método de trabajo y las fuentes empleadas: «Algunas fuentes para el estudio de la propiedad inmobiliaria»; «El Registro de la propiedad y el análisis geográfico de la propiedad urbana y territorial»; «El estudio de la propiedad urbana enEspaña. Una reflexión metodológica». La ampliación de los espacios de análisis de la propiedad urbana y la promoción inmueble a otros ámbitos madrileños o referidos al conjunto de la ciudad de Madrid: «Los orígenes de la propiedad inmobiliaria en el Extrarradio Norte de Madrid»; «La Ciudad Lineal y la práctica inmobiliaria de la Compañía Madrileña de Urbanización (I894I93I)»; «La propiedad urbana de Madrid en la primera mitad del siglo XIX»; «La promoción inmueble en el Madrid del siglo XIX»; «Catastros y crecimiento urbano en el Madrid del siglo XIX»; «Crecimiento espacial y mercado del suelo periférico 
en los inicios de la Restauración»; «Propiedad rústica y promoción inmobiliaria en el municipio de Madrid»; «La gran propiedad y la gran promoción residencial en Madrid»; «Políticas del suelo en Madrid»; «Propiedad urbana, promoción inmueble y Catastro en el Madrid de hoy». También abordó con el mismo presupuesto el conjunto nacional: «La promoción inmobiliaria en los ensanches del siglo XIX»; «El mercado inmobiliario en España»; «La promoción inmueble en España (I846I995)»; «Periferias urbanas y nuevas formas espaciales». Y dio el salto a México con dos estudios pioneros: «Notas sobre la propiedad del suelo y la formación del plano en la ciudad de México» y «Propiedad inmueble, morfología urbana y precios del suelo en Guadalajara (México) en el siglo XIX».

En tercer lugar llevó a la práctica su interés en consolidar una línea de colaboración con el propósito de continuidad entre dos disciplinas afines, la Geografía y la Historia. En febrero de 2002 se celebró en la Casa de Velázquez el Seminario dedicado a Propiedad urbana y crecimiento de la ciudad, que coordinó junto con Philippe Lavastre. Participaron diecisiete investigadores con enfoques procedentes de tres países, España, Francia e Italia, con una dinámica urbana muy similar. Allí se intercambian ideas y métodos, y las intervenciones se publican en 2005. La estrecha colaboración entre disciplinas la pone de manifiesto Rafael Mas en su participación «El estudio de la propiedad urbana en España». En ella se evidencia el carácter interdisciplinar del campo de estudio, en el que geógrafos, historiadores, arquitectos, historiadores del arte y juristas se aúnan al margen de su filiación original, dando constancia de ello la bibliografía que recoge para construir el discurso.

En cuarto lugar destaca su última aportación de 2003: La presencia militar en las ciudades. Orígenes y desarrollo del espacio militar en España. Fueron dos años de trabajo para abrir una nueva línea de investigación de gran trascendencia e imprescindible para seguir mejorando la explicación de los procesos de crecimiento y configuración de muchas ciudades, empleando un enfoque que mucho tiene que ver con el característico de su metodología de investigación. El libro se circunscribe a la ciudad del siglo XIX y primer tercio del XX. El autor se sumerge en archivos y bibliotecas militares para desentrañar la relación entre los poderes civil y militar, entre lo militar y lo urbano y su plasmación espacial. Y tenía la intención de proseguir el estudio en el futuro hasta llegar al desmantelamiento de las instalaciones militares que se estaban produciendo, como lo demuestra el proyecto de investigación iniciado sobre «La reconversión de suelo militar de Madrid y su reutilización en los últimos veinticinco años».

Para terminar quisiera incorporar algunas apreciaciones más allá de lo dicho hasta ahora sobre la tesis doctoral de Rafael Mas. Proceden de tres personas a las que sé que Rafael respetaba y admiraba en mucho por su buen quehacer científico. Señala Josefina Gómez Mendoza que «estudió los mecanismos de construcción de la ciudad de los siglos XIX y XX partiendo del papel de propietarios del suelo y promotores con una profundidad y una inteligencia que hicieron que sus claves interpretativas se convirtieran en argumento de autoridad para geógrafos, arquitectos, urbanistas, estudiosos de la ciudad en general». Horacio Capel apunta que «su tesis doctoral sobre el Ensanche de Madrid es una aportación de primer orden para el conocimiento del desarrollo urbano de esa ciudad, y constituye, además, 
una referencia metodológica ineludible para el estudio de esta forma de expansión urbana y el conocimiento de las ciudades españolas». Para Francisco Quirós la tesis «le convertía en uno de los valores más sólidos de la Geografía urbana en España, y en un ejemplo de la fertilidad del magisterio de Manuel de Terán. En esta obra estaban ya bien explícitos el rigor metodológico, la sagacidad y la congruencia que caracterizaron, hasta el final, la obra y la personalidad de Rafael Mas».

Solo añadir que al quehacer intelectual de Rafael le acompañaban una serie de capacidades que conformaban su temperamento de investigador e hicieron posible su obra continuada durante más de treinta años: inquietud, curiosidad, dedicación, tesón, rigor, honradez, generosidad y modestia. Pero también otras más personales que también contribuyeron a ello y le adornaban aún más. Pero esas pertenecen a la esfera privada que, con el permiso de todos, me reservo.

Dolores Brandis

\section{DOLORES BRANDIS GARCÍA: EL PAISAJE RESIDENCIAL EN MADRID}

Aurelio Nieto Codina. Departamento de Geografía, Universidad Nacional de Educación a Distancia.

Entre la diversidad de paisajes asociados a la acción antrópica, la ciudad ha tenido un papel destacado en la larga tradición de la Geografía Humana. Los espacios construidos con una finalidad residencial son un objeto de estudio desarrollado por la escuela geográfica francesa sobre todo a partir del trabajo pionero de R. Blanchard. D. Brandis, siguiendo esta corriente, pone el paisaje residencial en relación con las características de sus habitantes y con las fuerzas sociales que lo generan, dejando de lado aspectos considerados en esta tradición geográfica como la topografía y el emplazamiento. En la particular metodología empleada en este tipo de estudios, se suelen fusionar; por un lado, elementos visuales plenamente paisajísticos, los edificios; por otro lado, los aspectos demográficos, la población y todo lo referente al factor humano de los espacios urbanos.

Tanto Manuel de Terán como varios de sus discípulos y doctorandos lograron crear dentro de esta tendencia algunas obras esenciales; en este sentido, el libro de Dolores Brandis El paisaje residencial en Madrid es un ejemplo de obligada referencia. Lo mejor que se puede decir de este trabajo es que desde su aparición ha condiciona nuestra percepción de la ciudad y nuestro manera de acercarnos al paisaje madrileño, una vez leída la obra ya no vemos Madrid con los mismos ojos de antes. Cuando paseamos por las calles de la gran urbe mesetaria y observamos los edificios, las calles y las plazas, se activa en nuestra mente un resorte que procede de la lectura de esta obra; así, de manera nítida, se nos presentan en la imaginación el parcelario, las estructuras de las viviendas, su alzado y, al mismo tiempo, las fuerzas sociales que generaron los espacios habitados de esta ciudad. La urbe como lugar de vida de los ciudadanos y como espacio ocupado por las viviendas, un tema que nos ilustra de una de las necesidades humanas más inmediatas. 


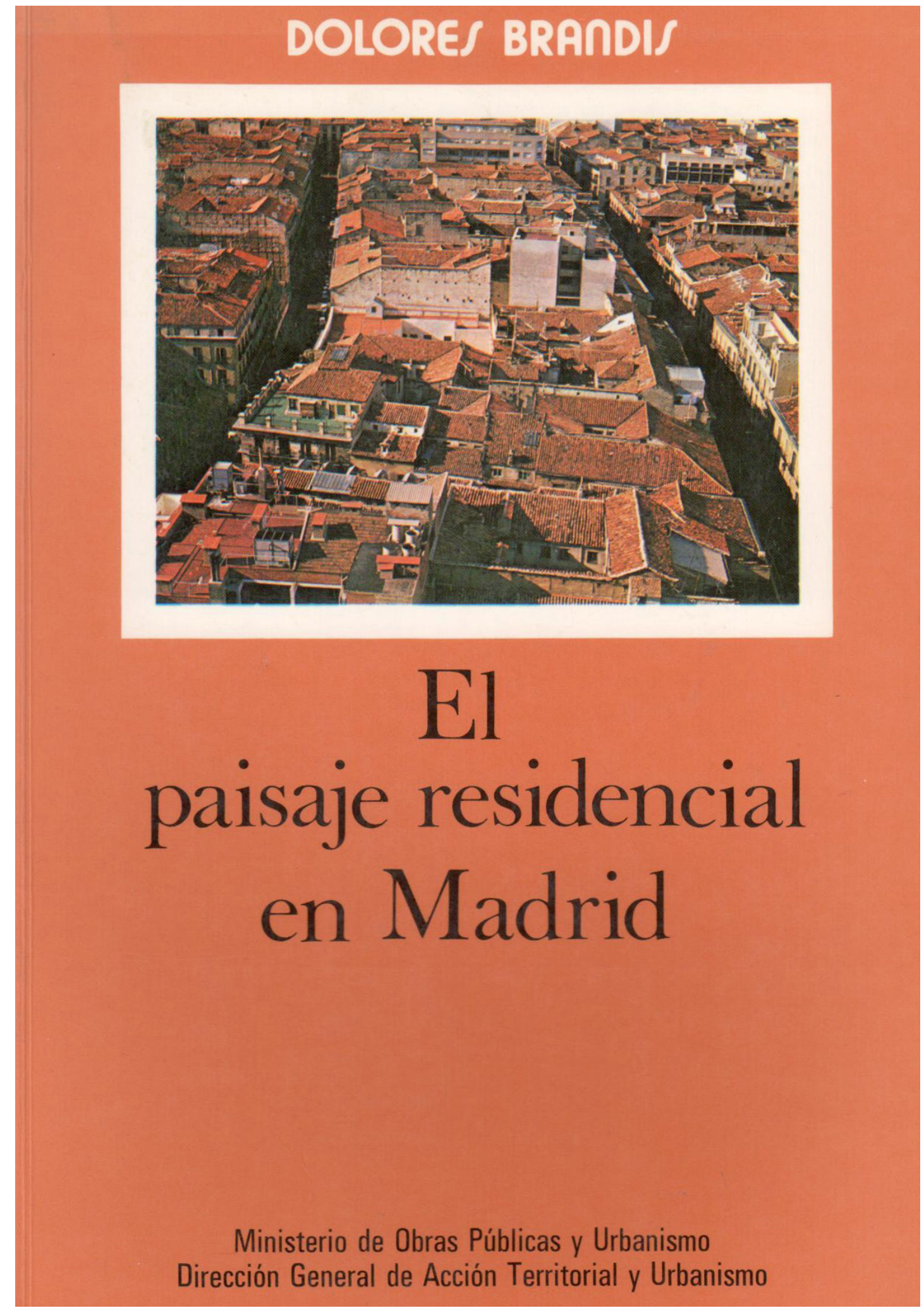


La vivienda es tal vez el elemento fundamental del paisaje urbano, pero no el único, necesitamos de otros componentes para tener una visión más completa de la ciudad, al menos en un primer acercamiento no se pueden olvidar los espacios libres (calles, plazas, jardines, etc.). La propia autora nos ayuda a completar nuestra comprensión del paisaje urbano madrileño con otra obra en la que se afronta el estudio de los espacios libres más relevantes de la ciudad: las plazas ${ }^{10}$

En casi todos los trabajos de esta investigadora tiene un peso importantísimo todo lo referente a la evolución histórica de la ciudad, por otro lado, una constante en los trabajos dirigidos por Manuel de Terán. Con este objetivo se manejan fuentes históricas de muy variada procedencia: legajos del Archivo de Villa, testimonios de escritores, propuestas de regidores, censos y parcelarios históricos, memoriales, documentos del planeamiento municipal, etc. Esta heterogeneidad en la procedencia de las fuentes favorece que la visión general del paisaje madrileño sea muy rica y variada, perfilando hasta los más mínimos detalles del mismo. De todos modos, se detecta un predominio de la documentación de tipo ordenancista (para los periodos previos al siglo XX) y de los datos procedentes del planeamiento para fechas más recientes, es por ello que en la explicación histórica tienen una presencia extraordinaria las decisiones procedentes de los poderes municipales, aunque no como condicionantes únicos, ya que en Madrid, las iniciativas particulares tienen un papel clave. La planificación municipal se presenta también como una fuente de conocimiento que en sus propias decisiones es testimonio a veces de realidades ya consolidadas.

El título original de la tesis nos ayuda a entender la naturaleza profunda del trabajo: «La evolución histórica del paisaje residencial en Madrid». Es por lo que gran parte de la publicación dedica su espacio a la historia de la vivienda en Madrid, seis capítulos de siete que suman el total. Este interés por lo histórico aparece incluso en el último capítulo, que es una completa tipología del espacio residencial del Madrid de i970.

Ya se ha señalado, acertadamente, que el acercamiento a los aspectos paisajísticos dibujado en esta obra incluye aspectos descriptivos al tiempo que incorpora elementos explicativos junto al tradicional acercamiento a la funcionalidad urbana. El paisaje residencial se liga aquí sobre todo al planeamiento y a la estructura de la propiedad ${ }^{\mathrm{II}}$, una opción metodológica recurrente en trabajos de otros discípulos de M. de Terán (Ruiz Palomeque Mas Hernández, del Río, etc.).

El último capítulo de la obra de Brandis se dedica al análisis del paisaje urbano existente en los años setenta del siglo XX y al establecimiento de tipologías derivadas de las formas del parcelario y de las construcciones, estableciendo unas fichas-tipo muy bien singularizadas. Es muy significativo que su situación estratégica en la última parte del libro permita que puedan considerarse también como una conclusión general de lo expuesto en los capítulos previos del libro. En esta parte

10. BrandIS (1983). Ampliación de un trabajo dirigido por M. de Terán: Urbanización de las plazas de Madrid (1972).

11. VILAGRASA (1991) 
final se presentan un conjunto de paisajes específicos (casco antiguo, ensanche, extrarradios históricos, periferia reciente) de los que previamente se ha analizado su origen y evolución histórica, partiendo como ya hemos señalado de las políticas urbanas y de las características demográficas, para presentar una formas urbanas que se hacen explícitas tanto en los parcelarios, como en los tipos edificatorios, los alzados del caserío y las características generales de las viviendas. Para alcanzar este objetivo se despliega una «iconografía geográfica» (fotos aéreas, planos, fotos de la autora a pie de calle) que es ejemplar y ha sido seguida como modelo en otros trabajos geográficos posteriores.

Antes del desarrollo de la metodología geográfica marxista procedente del paradigma anglosajón, $M$. de Terán y sus discípulos ya tenían un interés marcado por los problemas de segregación social y por las desigualdades en el ámbito de las ciudades, teniendo presente en sus trabajos las diferentes condiciones de acceso a bienes y servicios por parte de los ciudadanos como síntoma de injusticia social. Este es un aspecto evidente en el trabajo de Dolores Brandis especialmente en los últimos capítulos.

Es de todos sabido que la elección de un tema para una tesis doctoral condiciona la posterior carrera investigadora, ya que el tema elegido persigue durante años al doctorando y luego casi es un elemento de su andadura académica. Esto es especialmente claro en la obra de la autora del paisaje residencial en Madrid. En fechas más recientes, como queda de manifiesto en la bibliografía adjunta,ha mantenido un interés persistente por los nuevos paisajes residenciales madrileños, ampliando su tesis inicial con interesantes aportaciones que sirven de complemento a los datos iniciales expuestos correspondientes a 1970. Los ensanches (PAUs) creados en la periferia de la capital (Las Tablas, Montecarmelo, Sanchinarro, etc.) y en general el crecimiento urbano generado en el último cuarto de siglo han tenido su reflejo en publicaciones en las que no solo se describen y se acompañan las explicaciones de una novedosa iconografía geográfica, sino que se sigue incidiendo en los problemas sociales. Es decir, cuando se establece una relación entre estos desarrollos urbanos y la creación de burbuja inmobiliaria española. Un problema generado entre I986 y I882, pero que tuvo sus consecuencias sobre todo a partir de 2007-2008 cuando su estallido generó las consecuencias que han llevado a la profundización de la actual crisis inmobiliario.

La crisis inmobiliaria no afecta exclusivamente al volumen construido, tiene sobre todo su reflejo en la evolución de los precios de las viviendas. Un fenómeno que existía en el pasado y reaparece también en estos nuevos barrios, evidente en los PAU del norte, Sanchinarro, Las Tablas y Montecarmelo, donde los precios medios de la vivienda en 2009 son superiores a los de Vallecas o Carabanchel. Estamos por tanto ante un indicador de desigualdad espacial ${ }^{12}$. Ya en 2003 los barrios del norte se situaban con una mejor valoración económica, pues en ellos el precio

12. BRANDIS (2010). 
del $\mathrm{m} 2$ construido oscilaba entre 3.350 y 3.600 euros, mientras que en Carabanchel y Vallecas no sobrepasaba los 2.600 euros $^{13}$.

En resumen, el interés temático por la evolución del paisaje residencial en Madrid, contemplado desde una amplia gama de argumentos explicativos, llena la obra de esta geógrafa a lo largo de más de treinta años.

\section{OLIVERA POLL, ANA. LA ENSEÑANZA EN MADRID: ANÁLISIS DE UNA FUNCIÓN URBANA}

Carlos J. Pardo Abad. Departamento de Geografía, Universidad Nacional de Educación a Distancia.

El libro que aquí tenemos la oportunidad de presentar, con gran satisfacción personal por lo que representa la obra y su autora, es el resultado de la tesis doctoral de $\mathrm{D}^{\mathrm{a}}$ Ana Olivera, dirigida por el profesor D. Manuel de Terán, siendo defendida en la Universidad Complutense en el mes de marzo del año i977. El trabajo obtuvo la máxima calificación de sobresaliente cum laude y posteriormente Premio Extraordinario de Doctorado en la referida universidad. La autora fue durante un tiempo becaria del Consejo Superior de Investigaciones Científicas y de la Universidad Complutense, pasando posteriormente a incorporarse como profesora contratada y después como Profesora Titular de Geografía Humana en la Universidad Autónoma de Madrid, donde alcanzó finalmente la acreditación a Cátedra.

Es una obra de gran interés desde el punto de vista de la Geografía Urbana, en la que la autora se enfrenta, con magníficos resultados, a un tema verdaderamente relevante para el conocimiento de la ciudad como espacio humanizado, de contrastes y oportunidades, de desigualdades y problemas.

El estudio toma a la enseñanza como una función urbana, observando tanto las características del equipamiento educativo en el nivel primario y secundario como su evolución y dinámica de cambio en la ciudad de Madrid, las dotaciones asociadas, la tipología y tamaño de los centros, la escasez de espacio para nuevas zonas escolares, la enseñanza universitaria y sus ámbitos de atracción de estudiantes, etc. Todo un abanico de propuestas en las que el análisis objetivo, a través de numerosos datos estadísticos, cede paso en múltiples ocasiones a las reflexiones personales de carácter subjetivo, siempre atrayentes, sugerentes y, con el paso del tiempo y la perspectiva que ello ofrece, acertadas.

Aspectos muy relevantes que convierten a esta investigación en una tesis funcionalista alejada de las descripciones de espacios concretos, tan características de la denominada Geografía «clásica» o «regional», imperante en España durante bastantes décadas y hasta fechas no demasiado lejanas.

A la vez, este estudio podría encuadrarse en el arranque de la denominada Geografía de los Servicios Públicos o de la Geografía del Bienestar en nuestro país, disciplinas por otra parte más desarrolladas desde fechas muy tempranas en los países

13. BRANDIS \& del Río (2007). 


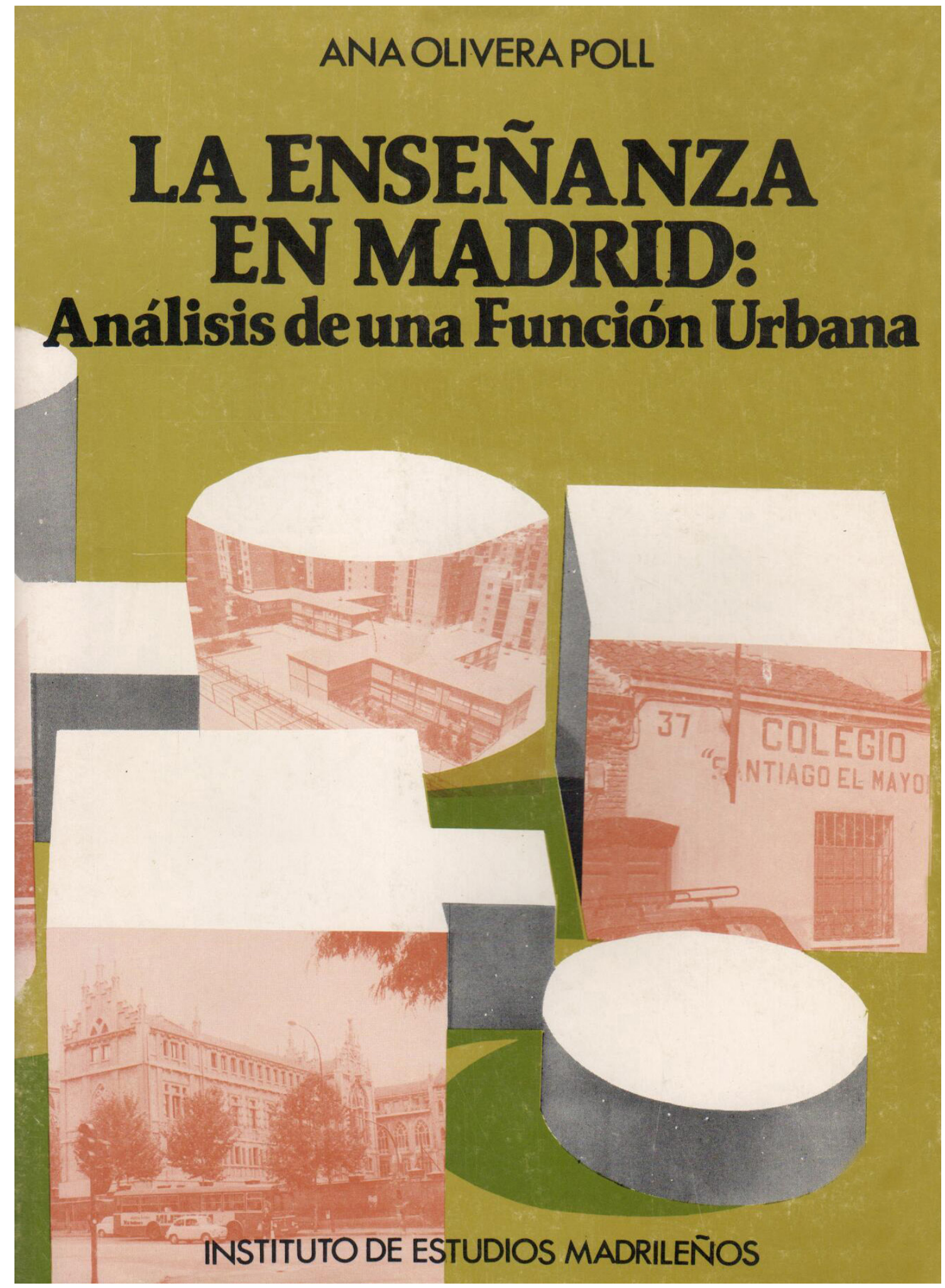


del ámbito anglosajón. La tesis de $\mathrm{D}^{\mathrm{a}}$ Ana Olivera es un ensayo de valoración de un servicio clave en un momento histórico muy concreto de modernización y cambio de la sociedad madrileña, en el paso siempre complicado de la dictadura a la democracia, y de transformación gradual de la mayor parte de los valores vinculados a la enseñanza.

Es una tesis muy centrada en lo social, lo que la convierte en una investigación innovadora en su tiempo, una tesis de Geografía Social que introduce aspectos tales como el análisis de la escuela como lugar deseado de encuentro de alumnos de diferentes clases sociales y el papel que ello desempeña, en contra de cualquier segregación, a favor de la renovación de la sociedad urbana en su conjunto.

Por otro lado se abordan algunos temas completamente modernos y al estilo de nuestros tiempos y preocupaciones más recientes, como el acceso de la mujer a la universidad. Una cuestión de género que la autora introduce a manera de reflexión crítica en torno a la situación tradicional de la mujer en relación con la educación. Y como oportunidad para constatar la dicotomía que a ese respecto existía entre las grandes áreas metropolitanas (Madrid, por ejemplo) y otros núcleos urbanos menores o áreas rurales.

Las diferencias de participación de la mujer entre los estudios más feminizados (Magisterio, Filosofía y Letras y Farmacia) con el resto de estudios (como los correspondientes a las Escuelas Técnicas Superiores) introducen una perspectiva muy interesante para las fechas en las que se realiza la investigación. La autora lo supo analizar con inteligencia, aproximándose de forma seguramente deliberada a los estudios de desigualdad tan característicos de la Geografía Radical. Sin lugar a dudas, este apartado habría merecido un mayor desarrollo dentro de la investigación por el interés que aún despierta en esta segunda década del siglo XXI.

Las proyecciones de población, el nivel de instrucción como reflejo de la situación socioeconómica de la ciudad, el papel del Estado, de la Iglesia y de otras instituciones privadas en el complejo mundo de la enseñanza, el impacto de esta función en el espacio urbano en temas tan fundamentales como la movilidad, el transporte y como motor desencadenante de otras funciones, son elementos añadidos de análisis que quedan abordados perfectamente en el estudio.

En su conjunto, completan un análisis muy amplio en el que, en cualquier caso, se echa en falta un capítulo de conclusiones generales en el que se podrían haber confirmado, o no dependiendo de los propios avances del estudio, algunas de las hipótesis o ideas previas que se encuentran inmersas a lo largo de la investigación. Tal vez existiesen razones de tipo editorial, tan frecuentes en las publicaciones de trabajos con las características del que aquí estamos presentando, que estuviesen en la base de la citada ausencia.

La metodología empleada, como la propia autora reconoce, refleja la inexistencia de trabajos previos sobre un tema similar, que habrían servido de referentes indiscutibles sobre los que construir el complejo edificio conceptual. Esta carencia, es evidente, marca de algún modo el estudio, pero lo enriquece desde el punto de vista científico por el valor comparativo de los métodos aplicados, las fuentes consultadas en diferentes organismos, tanto publicadas como de carácter inédito, y los resultados alcanzados. 
El aporte gráfico es muy abundante y expresa muy correctamente el papel de la educación como función urbana en Madrid. Son muchas las pirámides de población elaboradas, los mapas generales de la ciudad y de los distintos distritos en los que esta se dividía a mediados de la década de I970, para la localización exacta de centros educativos o para establecer áreas de influencia dentro del espacio urbano.

Las fotografías de la autora reflejan un intenso trabajo durante los años de elaboración de la tesis doctoral. A través de este valioso material, ventana abierta a una realidad urbana que entonces fue y tras varias décadas dejó de ser en algunos casos, se constata una interpretación de la disciplina geográfica como la «ciencia de andar y ver», tan del gusto de su maestro y director de tesis, D. Manuel de Terán, a la par que indiscutible referente intelectual y personal para la autora.

La claridad expositiva de la obra se aprecia a lo largo de todas sus páginas. Es un rasgo indiscutible de la obra, así como la extraña racionalidad en el manejo analítico de la información. Y decimos lo de extraña racionalidad porque contrasta con la pasión personal que caracteriza a la autora en todo aquello en lo que se implica y la implica, la efervescencia solo aparentemente caótica de ideas, la visión intimista y subjetiva (casi irreal, pero también premonitoria) del territorio, la denuncia de lo injusto y la intuición mágica para captar las complejas relaciones de los distintos elementos geográficos en el espacio.

Una persona de gran valía científica que podría quedar situada a caballo entre una herencia que prolonga, inconscientemente, caminos del pasado en su presente y la superación intencionada de lo meramente temporal y espacial para lograr alcanzar una especie de «metageografía» en la que los límites futuros quedan fijados por el papel indiscutible de las emociones. 


\section{BIBLIOGRAFÍA}

Catálogo Exposición (2007). Manuel de Terán, I904 - 1984, Madrid, Sociedad Estatal de Conmemoraciones Nacionales - Residencia de Estudiantes.

BRANDIS, D. (1983). El paisaje residencial de Madrid, Madrid, M.O.P.U.

—, (I983). «Forma y función de las plazas de Madrid», Estudios geográficos, Vol. 36, I38-I39, I975 Pp. I25-I56

BRANDIS, D.; Rio I. del (I999): «Diez años creando periferia en Madrid», en Domínguez, R. (coord.): La ciudad. Tamaño y crecimiento, Departamento de Geografía / AGE, Málaga, pp. 267-276.

BRANDIS, D.; Rio I. del (2007): «Los últimos desarrollos urbanos en la periferia de la ciudad de Madrid», en Artigues, A. et al. (eds): Los Procesos urbanos postfordistas, Palma de Mallorca, AGE y Universidad de Les Illes Balears, pp. 7I-87

BRANDIS, D. (20I0). «Los grandes desarrollos residenciales de la periferia de Madrid: de la burbuja a la crisis inmobiliaria» X Coloquio y jornadas de campo de Geografía urbana, Oviedo-Santader-Bilbao, I8 p.

MAs, R. (I982). El barrio de Salamanca. Planeamiento y propiedad inmobiliaria en el Ensanche de Madrid, Madrid, l.E.A.L.

-, (I978). «El plano parcelario del sector nordeste del ensanche de Madrid», Ciudad y Territorio, 2, pp. 25-48

—, (I978, bis). «Tipos de vivienda en el Ensanche Nordeste de Madrid», Estudios Geográficos, I52, pp. 307-46.

Olivera, A. (1978). La enseñanza en Madrid: análisis de una función urbana, Madrid, Instituto de Estudios Madrileños.

-, (I98I). «Desdotación escolar y cambio de uso en el Ensanche», en: Madrid, Estudios de Geografía Urbana / coord. por Manuel de Terán, pp. I6I-I84.

Teran, M. (I976), «Prologo», en Julio Vinuesa Angulo, El desarrollo metropolitano de Madrid: sus repercusiones geodemográficas, Madrid, Instituto de Estudios Madrileños, pp. 9-I2.

VILAGRASA, J. (I99I). «El estudio de la morfología urbana: una aproximación», Geocrítica, 92. $<$ http://www.ub.edu/geocrit/geog2.htm> (consultado: 07/07/2015). 


\section{SERIE VI GEOGRAFÍA}

REVISTA DE LA FACULTAD DE GEOGRAFÍA E HISTORIA
AÑOS 2015-2016

ISSN: $1130-2968$

E-ISSN 2340-146X

\section{8-9 ESPACIO, TIEMPO \\ Y FORMA}

14

PRESENTACIÓN · ForEWORD

\section{Artículos · Articles}

15

Carlos Alberto Abalerón

Diferencias innatas y desigualdades socio-espaciales de Calidad de Vida en San Carlos de Bariloche, Argentina / Innate differences and socio-spatial inequalities Quality of Life in San Carlos de Bariloche, Argentina

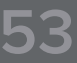

NATACHA CALVET TAPIA

Las prácticas lúdicas en la calle y la imagen del centro de la ciudad en Santiago de Chile / Recreational practices on the street and the image of the city center of Santiago de Chile

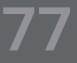

ENRIQUE dE Rosa GIOLITO

Las Complejas relaciones entre paisaje, puerto, ciudad y sus efectos en el patrimonio cultural en la bahía de Pasaia / The complex relationships between landscape, harbor, town and its effects on cultural heritage in the bay of Pasaia

\section{3} ANa María López ORTEgo

¿Quién está contra quién en los cerros orientales de Bogotá?. La perspectiva local desde el barrio la Cecilia / Who is against who in the eastern hills of Bogotá? - the local perspective from the neighborhood of la Cecilia

JULIO LÓPEZ-DAVALILLO LARREA

Las eurociudades rayanas / The ecocities bordering

\section{Beatriz Martínez de Teresa}

Estudio de los recursos hídricos en España: Análisis y caracterización en la Cuenca del Tajo / Study of water resources in Spain:Analysis and characterization in the Tajo Basin

Francisco José Morales YAgo

La incorporación de los portafolios electrónicos en el proceso enseñanza-aprendizaje y evaluación de la geografía en el alumnado de educación a distancia / The incorporation of electronic portfolios learning in geography and evaluation process in distance education students
24. MARcos ORTEga Montequín parado de tres casos en Asturias / Agrological potential in rural land planning; comparative study of three cases in Asturies

269 José Ramón SÁnchez Holgado

Las torres y atalayas de la costa tropical. ¿un recurso turístico pendiente de explotación? / The towers and watchtowers of the Costa Tropical.an Outstanding tourist resource exploitation

287

OSÉ RAMÓn SÁNCHEZ HOLGADO

Inundaciones en la rambla Albuñol. Causas y posibles medidas de intervención / Floods in Albuñol dry riverbed. Causes and possible intervention

\section{Reseñas · Book Review}

319 Yi-fu Tuan. (2015). Geografía romántica. En busca del paisaje sublime. Editado por Biblioteca nueva. Colección: Paisaje y teoría. Edición de Joan Nogué. 177 pp. ISBN: 978-84-16345-15-1 O (AURELIO NiETo CodinA)

323 Bosque Maurel, Joaquín (2011): Granada. Historia y cultura. Granada 323 Diputación Provincial de Granada-Libros de la Estrella, 210 pp. ISBN: 978-84-7807-510-2 (Alejandro García Ferrero)

\section{Imágenes y palabras · Pictures and words}

329 Francisco josé Morales Yago

Las salinas de Imón (Guadalajara): un paisaje cultural de gran valor histórico / The saltworks of Imón (Guadalajara): a cultural landscape of great historical value

\section{Historia de la Geografía Española · History of Geography in Spain}

335

Aurelio Nieto Codina, Dolores Brandis García, Carlos Pardo Abad Tres tesis doctorales dirigidas por don Manuel de Terán; el paisaje residencial en Madrid (Dolores Brandis), la enseñanza en Madrid (Ana Olivera) y el barrio de Salamanca (Rafael Más) / Three thesis directed by don Manuel Terán; residential landscape in Madrid (Dolores Brandis) teaching in Madrid (Ana Olivera) and the Salamanca district (Rafael Más) 